\title{
Aporte de matéria seca por raízes e parte aérea de plantas de cobertura de verão
}

\section{Input of dry matter by roots and shoots of summer cover crops}

\author{
Cristiane de Conti Medina ${ }^{1}$; Carmen Silvia Vieira Janeiro Neves ${ }^{1 *}$; \\ Celso Aita ${ }^{2}$; Ivan Bordin ${ }^{3}$; Edilene Preti ${ }^{3}$; Paulo Vicente Contador Zaccheo ${ }^{3}$; \\ Ricardo Sfeir de Aguiar ${ }^{3}$; Segundo Urquiaga ${ }^{4}$
}

\section{Resumo}

As vantagens do uso de plantas de cobertura ou adubos verdes nos sistemas de produção já são bem conhecidas, mas pouco se sabe sobre a contribuição do sistema radicular dessas plantas no estoque de matéria orgânica do solo em profundidades maiores que $0,30 \mathrm{~m}$, nas quais têm sido relatados maiores efeitos do manejo do solo, principalmente em regiões de clima tropical e subtropical. O objetivo do trabalho foi avaliar os aportes de matéria seca, $\mathrm{C}$ e N e a densidade de comprimento radicular até $1,0 \mathrm{~m}$ de profundidade de plantas de cobertura de verão (feijão-de-porco, mucuna cinza, Crotalaria juncea e milheto), bem como a profundidade efetiva das raízes e a relação parte aérea/sistema radicular (PA/SR), em sistema de sucessão de milho - nabo forrageiro - aveia mais ervilhaca. As raízes foram amostradas em sete profundidades $(0-0,10 ; 0,10-0,20 ; 0,20-0,30 ; 0,30-0,40 ; 0,40-0,60 ; 0,60-0,80$ e $0,80-1,00 \mathrm{~m})$. O delineamento experimental foi em blocos ao acaso com seis repetições. Os resultados foram submetidos à análise de variância e teste de Tukey. Apesar de o milheto fornecer mais massa seca $\left(3,58 \mathrm{Mg} \mathrm{ha}^{-1}\right)$ proveniente da parte aérea (PA), sua contribuição em $C$ do sistema radicular foi menor do que a da $C$. juncea; para o C, a relação PA/SR do milheto foi de 1,46 enquanto que a da C. juncea foi de 0,75 . Entre as espécies estudadas, o sistema radicular da C.juncea aporta maior quantidade de carbono $(1,40 \mathrm{Mg}$ $\left.\mathrm{ha}^{-1}\right)$ do que os demais, enquanto que as raízes da mucuna cinza contribuem com a maior quantidade de nitrogênio $\left(72,38 \mathrm{~kg} \mathrm{ha}^{-1}\right)$ ao solo, considerando a profundidade de até $1,0 \mathrm{~m}$.

Palavras-chave: Manejo do solo, sistema radicular, adubação verde, sucessão de culturas, biomassa

\begin{abstract}
The advantages of using cover crops or green manures are already well known, but little is known about the contribution of the root system of these plants in the stock of organic matter in the soil. The aim of this study was to evaluate the dry matter, carbon and nitrogen supply by above ground parts and roots (down to $1.0 \mathrm{~m}$ deep) of cover crop plants (Jack-bean - Canavalia ensiformis; velvet bean Stizolobium niveum Kuntze; Crotalaria juncea L.; and millet - Pennisetum americanum), in sequence of corn - turnip - oat plus vetch. Trenches were dug and roots samplings were collected at seven depths $(0-0.10 ; 0.10-0.20 ; 0.20-0.30 ; 0.30-0.40 ; 0.40-0,60 ; 0.60-0.80$; and $0.80-1.00 \mathrm{~m})$. The experimental design was randomized blocks and the results were submitted to ANOVA and Tukey test. Despite millet
\end{abstract}

\footnotetext{
${ }^{1}$ Eng $^{\text {as }}$ Agr $^{\text {as }}$, Prof ${ }^{\mathrm{a}} \mathrm{s}$. Dr ${ }^{\mathrm{a}} \mathrm{s}$. da Universidade Estadual de Londrina, UEL, Londrina, PR. Bolsista Produtividade do CNPq. E-mail: medina@uel.br; csvjneve@uel.br

${ }^{2}$ Eng $^{\circ}$ Agr $^{\circ}$, Prof. Dr. da Universidade Federal de Santa Maria, Santa Maria, RS. Bolsista Produtividade do CNPq. E-mail: celsoaita@gmail.com

${ }^{3}$ Eng $^{\mathrm{O}_{\mathrm{s}}} \mathrm{Agr}^{\mathrm{Os}}$, Discente(s) de Doutorado em Agronomia, UEL, Londrina, PR. E-mail: ivanbordin@hotmail.com; edipretti2006@ yahoo.com.br; pvczaccheo@yahoo.com.br; rsaguiar@hotmail.com

${ }^{4}$ Eng $^{\text {o }}$ Agr $^{\text {o }}$, Pesquisador, Embrapa Agrobiologia, Seropedica, RJ. Bolsista Produtividade do CNPq. E-mail: urquiaga@cnpab. embrapa.br

* Autor para correspondência
} 
presented the highest dry mass input $\left(3.58 \mathrm{Mg} \mathrm{ha}^{-1}\right)$ from above ground part (AGP), its C contribution from root system (RS) was lower than C. juncea, because AGP/RS millet relation was 1.46 while this value for $\mathrm{C}$. juncea was 0.75 . Among the evaluated green manures, the roots of $C$. juncea contribute the most carbon $\left(1.40 \mathrm{Mg} \mathrm{ha}^{-1}\right)$ than the others, while the roots of velvet bean contribute the largest amount of nitrogen $\left(72.38 \mathrm{~kg} \mathrm{ha}^{-1}\right)$ to the soil.

Key words: Soil management, root system, green manuring, succession planting, biomass

O carbono orgânico presente no solo vem sendo quantificado e estudado, visando a evitar sua transferência para a atmosfera e as consequências desse incremento (ZANATTA et al., 2007), pois os solos são os mais importantes reservatórios de carbono dos ecossistemas terrestres, contendo cerca de três vezes a quantidade de carbono da vegetação sustentada por eles (POST et al., 1982). O estoque de matéria orgânica do solo é afetado pelo grau de exposição do solo aos fatores que favorecem suas perdas, sua conservação ou até mesmo o seu aumento. Assim, o manejo com plantio direto, que minimiza o revolvimento do solo, em associação com a inclusão de adubos verdes, que produzam grande quantidade de massa, é um sistema que pode aumentar o seqüestro de carbono no solo (LOVATO et al., 2004; HOLANDA et al., 2011).

Tradicionalmente, quando se realiza a quantificação do aporte de material vegetal produzido pelas plantas, são considerados apenas os restos culturais provenientes da parte aérea, sem levar em consideração a contribuição do sistema radicular. Esse enfoque tem mudado e os trabalhos de pesquisa têm dado maior importância ao papel das raízes na preservação ou aumento da matéria orgânica do solo (GREGORY, 2006). A avaliação dessa contribuição é importante, porque o $\mathrm{C}$ radicular apresenta menor taxa de decomposição, quando comparado ao da parte aérea (BALESDENT; BALABANE, 1996). Rasse, Rumpel e Dignac (2005), analisando os resultados de vários trabalhos, estimaram que o $\mathrm{C}$ originado das raízes permanece no solo 2,4 vezes mais do que o $\mathrm{C}$ derivado da parte aérea por sua maor estabilidade. Bolliger et al. (2006) observaram que o $\mathrm{C}$ proveniente das raízes fica mais protegido da atividade microbiológica pela capacidade das raízes de penetrar nos microagregados do solo. Rasse, Rumpel e Dignac (2005) apontam também a proteção proporcionada pela interação com íons metálicos e por micorrizas e pelos radiculares.

Apesar da importância do C adicionado ao solo pelas raízes, pouco tem sido estudado sobre essa contribuição, principalmente na camada de 0,3 a $1,0 \mathrm{~m}$ na qual têm sido relatados os maiores efeitos do manejo do solo, principalmente em regiões de clima tropical e subtropical, como no trabalho de Boddey et al. (2010), no qual os autores analisaram os dados de três experimentos de longa duração com plantio direto e convencional no sul do Brasil e concluíram que, quando se comparam os manejos de plantio direto e convencional apenas até a profundidade de $0,30 \mathrm{~m}$ do solo, a diferença para o acúmulo anual de carbono a favor do plantio direto é pequena $(0,04 \mathrm{a}$ $\left.0,88 \mathrm{Mg} \mathrm{ha}^{-1}\right)$, enquanto que quando a comparação é feita de 0 a $1,00 \mathrm{~m}$ de profundidade o acréscimo em $\mathrm{C}$ pelo manejo conservacionista é bem mais significativo $\left(0,48\right.$ a $\left.1,53 \mathrm{Mg} \mathrm{ha}^{-1}\right)$.

Dessa maneira, é importante a identificação das espécies de adubo verde que têm maior capacidade de contribuir para o acúmulo de matéria orgânica em maiores profundidades do solo. O objetivo do trabalho foi avaliar os aportes de matéria seca, carbono e nitrogênio, a distribuição do sistema radicular, a densidade de comprimento de raízes e a profundidade efetivas das raízes de plantas de cobertura de verão até 1,0 $\mathrm{m}$ de profundidade.

O trabalho foi realizado no município de Santa

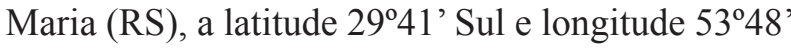
Oeste, com $95 \mathrm{~m}$ de altitude. O solo é classificado como Argissolo Vermelho Distrófico arênico (EMBRAPA, 1999), com textura superficial francoarenosa (109 $\mathrm{g} \mathrm{kg}^{-1}$ de argila, $244 \mathrm{~g} \mathrm{~kg}^{-1}$ de silte e 
$648 \mathrm{~g} \mathrm{~kg}^{-1}$ de areia) e subsuperficial franco-argilosa (295 $\mathrm{g} \mathrm{kg}^{-1}$ de argila, $284 \mathrm{~g} \mathrm{~kg}^{-1}$ de silte e $421 \mathrm{~g} \mathrm{~kg}^{-1}$ de areia) (ALBUQUERQUE; REINERT, 2001). O clima da região é subtropical úmido (Cfa2), com precipitação e temperatura médias anuais de 1561 mm e $19,3{ }^{\circ} \mathrm{C}$, respectivamente.

O ensaio foi conduzido em sistema de semeadura direta, desde 1998, em rotação: cinco plantas de cobertura de verão (fevereiro a maio), uma cobertura de inverno (aveia + ervilhaca, de maio a setembro) e uma cultura de verão (milho, de setembro a março). As coberturas de verão foram: 1) pousio, com vegetação espontânea com predominância de picão preto (Bidens subalternans DC.), gramaseda (Cynodon dactylon L.), falsa-serralha (Emilia sonchifolia (L) DC) e poaia (Richardia brasiliensis); 2) feijão-de-porco (Canavalia ensiformis ( L. ) DC.); 3) mucuna cinza (Stizolobium niveum Kuntze); 4) Crotalaria juncea (Crotalaria juncea L.); e 5) milheto (Pennisetum americanum).

As plantas de cobertura de verão foram semeadas manualmente, em fevereiro, entre as linhas do milho, que estava na fase de enchimento de grãos. O espaçamento utilizado foi de $0,45 \mathrm{~m}$, com 5; 5; 26 e 100 sementes por metro linear, respectivamente, para feijão-de-porco, mucuna cinza, crotalária juncea e milheto. Essas plantas foram cultivadas sem adubação química e manejadas com rolofaca no estádio de pleno florescimento, antes da semeadura das plantas de cobertura de inverno.

As avaliações foram realizadas no pleno florescimento, em maio de 2006. Para avaliação da parte aérea, foram usados quatro quadros de $0,7 \mathrm{X}$ $0,7 \mathrm{~m}$, após o manejo com roçadora. A matéria seca foi determinada em estufa a $65^{\circ} \mathrm{C}$ por 48 horas; para o carbono, foi utilizado o teor médio de $40 \%$ deste elemento na matéria seca (LOVATO et al., 2004); e o nitrogênio foi determinado segundo Tedesco et al. (1995).

$\mathrm{Na}$ amostragem das raízes, foi utilizado o método do trado modificado, com coleta por meio de anéis volumétricos (BÖHM, 1979). Para isso, foram abertas seis trincheiras por cultura avaliada, perpendicularmente à linha de plantio, com largura de $0,9 \mathrm{~m}$ e comprimento e profundidade de $1 \mathrm{~m}$. $\mathrm{Na}$ parede das trincheiras foram cravados anéis de ferro de $0,105 \mathrm{~m}$ de diâmetro por $0,10 \mathrm{~m}$ de altura, com volume de $8,65 \times 10^{-4} \mathrm{~m}^{3}$, com o auxílio de um esticador hidráulico, em sete profundidades $(0-0,10$; $0,10-0,20 ; 0,20-0,30 ; 0,30-0,40 ; 0,40-0,60 ; 0,60-$ 0,80 e $0,80-1,00 \mathrm{~m}$ ) e em dois locais em relação à planta (linha e entrelinha de plantio).

A separação das raízes de cada anel foi realizada com água corrente sobre peneira com malha de 1 $\mathrm{mm}$. As raízes foram submetidas à leitura ótica com scanner e analisadas pelo programa SIARCS 3.0 (JORGE et al., 1996), para obtenção do comprimento (cm). Os dados de comprimento das raízes foram expressos em densidade de comprimento radicular, em comprimento de raiz por volume de solo $(\mathrm{cm}$ $\mathrm{cm}^{-3}$ ), levando-se em conta a medida das raízes obtida com o SIARCS 3.0 e o volume dos anéis usados para amostragem. Essas avaliações foram realizadas até 1,0 $\mathrm{m}$ de profundidade. Calculou-se também a chamada profundidade efetiva das raízes, que é a profundidade do solo até onde se concentram $80 \%$ das raízes encontradas (KLAR, 1991).

As raízes foram levadas à estufa de ventilação forçada a $65^{\circ} \mathrm{C}$ por 48 horas, para determinação da matéria seca. Para determinação de carbono e nitrogênio foram feitas amostras compostas das raízes, com quatro subamostras por parcela (TEDESCO et al., 1995). A partir dos dados obtidos, foi feita relação entre o volume do anel $\left(8,65 \times 10^{-4}\right.$ $\mathrm{m}^{3}$ ) e a área do terreno (ha), determinando-se os conteúdos de matéria seca, carbono e nitrogênio por hectare.

O delineamento experimental utilizado foi de blocos ao acaso, com seis repetições. Os dados foram submetidos à análise de variância e teste de Tukey a $5 \%$ de probabilidade.

Os resultados evidenciam que para a matéria seca da parte aérea das plantas de cobertura de verão, o aporte proveniente do milheto $\left(3,58 \mathrm{Mg} \mathrm{ha}^{-1}\right)$ foi 
significativamente superior ao do feijão-de-porco $\left(2,22 \mathrm{Mg} \mathrm{ha}^{-1}\right)$, que, por sua vez, superou a mucuna cinza $\left(0,89 \mathrm{Mg} \mathrm{ha}^{-1}\right)$; enquanto que o aporte da Crotalaria juncea $\left(2,64 \mathrm{Mg} \mathrm{ha}^{-1}\right)$ foi maior apenas do que a da mucuna cinza, não se diferenciando do milheto e do feijão-de-porco (Tabela 1). Perin et al. (2004), na região da zona da mata mineira, obtiveram 7,12 $\mathrm{Mg} \mathrm{ha}^{-1}$ para milheto e 9,34 Mg ha $^{-1}$ para Crotalaria juncea. Com exceção do milheto, a massa seca produzida pela parte aérea dos adubos verdes no presente trabalho ficou abaixo do relatado por Bolliger et al. (2006), em uma revisão sobre o uso de adubos verdes no sul do Brasil. O baixo rendimento observado na produção de matéria seca pela parte aérea dos adubos verdes no presente trabalho se deve à ocorrência de baixas temperaturas no início do outono, entre abril e maio (aproximadamente $8{ }^{\circ} \mathrm{C}$ ), que ocasionaram injúrias, principalmente, na mucuna cinza e no feijão-de-porco. Isso fez com que essas duas espécies não atingissem o florescimento, enquanto que o milheto e a $C$. juncea conseguiram completar seus ciclos. Esta observação corresponde ao relato de Monegat (1991), de que mucuna e feijão-deporco são mais suscetíveis às baixas temperaturas quando comparados a $C$. juncea. Esse fator deve ser considerado na escolha das espécies de adubo verde e da época de plantio a serem usadas em determinada região.

Tabela 1. Aporte de matéria seca (MS), carbono (C) e nitrogênio $(\mathrm{N})$ pela parte aérea e do sistema radicular até 1,0 $\mathrm{m}$ de profundidade e relação parte aérea/sistema radicular (PA/SR) das plantas de cobertura de solo de verão. Santa Maria-RS, 2006.

\begin{tabular}{|c|c|c|c|c|c|c|c|c|c|}
\hline \multirow{3}{*}{ Variáveis } & \multicolumn{3}{|c|}{ Parte aérea } & \multicolumn{3}{|c|}{ Sistema radicular } & \multicolumn{3}{|c|}{ Relação PA/SR } \\
\hline & MS & $\mathrm{C}$ & $\mathrm{N}$ & MS & $\mathrm{C}$ & $\mathrm{N}$ & MS & $\mathrm{C}$ & $\mathrm{N}$ \\
\hline & \multicolumn{2}{|c|}{$\mathrm{Mg} \mathrm{ha}^{-1}$} & $\mathrm{~kg} \mathrm{ha}^{-1}$ & \multicolumn{2}{|c|}{$\mathrm{Mg} \mathrm{ha}^{-1}$} & $\mathrm{~kg} \mathrm{ha}^{-1}$ & & & \\
\hline Milheto & $3,58 a^{*}$ & $1,43 \mathrm{a}$ & $28,75 \mathrm{~b}$ & $3,56 \mathrm{a}$ & $0,98 \mathrm{~b}$ & $45,55 \mathrm{~b}$ & 1,01 & 1,46 & 0,63 \\
\hline Feijão-de-porco & $2,22 \mathrm{~b}$ & $0,88 \mathrm{~b}$ & $65,00 \mathrm{a}$ & 3,49 a & $1,12 \mathrm{ab}$ & $68,37 \mathrm{ab}$ & 0,64 & 0,79 & 0,95 \\
\hline Mucuna cinza & $0,89 \mathrm{c}$ & $0,35 \mathrm{c}$ & $25,50 \mathrm{~b}$ & $3,77 \mathrm{a}$ & $1,15 \mathrm{ab}$ & $72,38 \mathrm{a}$ & 0,24 & 0,31 & 0,35 \\
\hline C. juncea & $2,64 a b$ & $1,06 \mathrm{ab}$ & $49,00 \mathrm{ab}$ & $4,21 \mathrm{a}$ & $1,40 \mathrm{a}$ & $55,2 \mathrm{ab}$ & 0,63 & 0,75 & 0,88 \\
\hline $\mathrm{CV}(\%)$ & 24,45 & 24,44 & 32,47 & 28,06 & 27,75 & 26,08 & - & - & - \\
\hline
\end{tabular}

* Médias seguidas da mesma letra na coluna não diferem entre si, pelo teste de Tukey a 5\% de probabilidade de erro.

Fonte: Elaboração dos autores.

As diferenças observadas no aporte de carbono pela parte aérea das plantas de cobertura de verão foram iguais às ocorridas no aporte de matéria seca (Tabela 1). Os valores variaram de $0,35 \mathrm{Mg}$ ha $^{-1}$ para a mucuna cinza até $1,43 \mathrm{Mg} \mathrm{ha}^{-1}$ para o milheto. Vendruscolo et al. (2000) obtiveram resultados semelhantes, com média de $1,55 \mathrm{Mg} \mathrm{ha}^{-1}$, ao avaliarem Crotalaria juncea, feijão-de-porco e mucuna cinza, também em Santa Maria-RS.

Para o nitrogênio contido na parte aérea, o feijão-de-porco foi significativamente superior ao milheto e à mucuna cinza, não diferindo da $C$. juncea (Tabela 1). Essa diferença pode ser explicada pela baixa quantidade de nitrogênio contida no milheto, única espécie não fabacea avaliada, e pela baixa produção de matéria seca da mucuna cinza. Resultados semelhantes foram encontrados na literatura, como o baixo aporte de nitrogênio do milheto em comparação a feijão-de-porco e $C$. juncea (MARQUES et al., 2002) e a superioridade do feijão-de-porco no aporte de nitrogênio, em comparação à mucuna cinza (VENDRUSCOLO et al., 2000).

Apesar das diferenças ocorridas no desempenho da parte aérea dos adubos verdes e das injúrias provocadas pelo frio, não foram encontradas diferenças significativas para a matéria seca aportada pelo sistema radicular das plantas de 
cobertura (Tabela 1), provavelmente pela proteção ao frio oferecida pelo solo ao sistema radicular, que já se encontrava formado. Com isso, a relação $\mathrm{PA} / \mathrm{SR}$ referentes à MS foi de 1,01 para o milheto, sendo a única espécie a contribuir mais pela parte aérea do que pelo sistema radicular no aporte de matéria seca ao solo. O feijão-de-porco e a $C$. juncea tiveram relações PA/SR de 0,64 e 0,63, respectivamente, ficando a mucuna cinza como a cultura que teve maior contribuição do sistema radicular em relação à parte aérea, com relação PA/ SR de 0,24 (Tabela 1).
No aporte total de carbono pelas raízes, a $C$. juncea foi superior ao milheto, não diferindo de feijão-de-porco e mucuna cinza. As diferenças encontradas são atribuídas à maior porcentagem de carbono existente nas raízes da $C$. juncea $(33,27 \%)$ em relação ao milheto $(27,00 \%)$ (Tabela 1). Esta variação no teor de carbono das raízes em diferentes espécies também foi relatada por outros autores (BAZOT et al., 2005; HOKKA; MIKOLA; SETÄLÄ, 2004).

Tabela 2. Densidade de comprimento radicular e profundidade efetiva de raízes, matéria seca (MS), carbono (C) e nitrogênio $(\mathrm{N})$ até 1,0 m de profundidade das raízes das plantas de cobertura de solo de verão. Santa Maria-RS, 2006.

\begin{tabular}{llcccc}
\hline \multicolumn{1}{c}{ Variáveis } & Milheto & $\begin{array}{c}\text { Feijão-de- } \\
\text { porco }\end{array}$ & $\begin{array}{c}\text { Mucuna } \\
\text { cinza }\end{array}$ & $\begin{array}{c}\text { Crotalaria } \\
\text { juncea }\end{array}$ & CV $(\%)$ \\
\hline Densidade de comprimento radicular $\left(\mathrm{cm} \mathrm{cm}^{-3}\right)$ & $3,86 \mathrm{a}^{*}$ & $3,35 \mathrm{a}$ & $3,81 \mathrm{a}$ & $3,48 \mathrm{a}$ & 20,78 \\
Profundidade efetiva de raízes $\left(\mathrm{cm} \mathrm{cm}^{-3}\right)$ & $0,39 \mathrm{ab}$ & $0,30 \mathrm{ab}$ & $0,26 \mathrm{~b}$ & $0,40 \mathrm{a}$ & 18,13 \\
Profundidade efetiva da MS, C e N (m) & $0,38 \mathrm{a}$ & $0,30 \mathrm{ab}$ & $0,25 \mathrm{~b}$ & $0,35 \mathrm{a}$ & 16,15 \\
\hline
\end{tabular}

*Médias seguidas da mesma letra na linha não diferem entre si, pelo teste de Tukey a 5\% de probabilidade de erro.

Fonte: Elaboração dos autores.

A relação PA/SR, para o carbono foi semelhante à da matéria seca, sendo o milheto a única espécie a contribuir mais pela parte aérea do que pelo sistema radicular no aporte de carbono ao solo (Tabela 1), em razão das já relatadas injúrias pelo frio. $\mathrm{O}$ feijão-deporco e a $C$. juncea tiveram relações PA/SR de 0,79 e 0,75 , respectivamente; a mucuna cinza foi a cultura que teve maior contribuição do sistema radicular em relação à parte aérea, com relação $\mathrm{PA} / \mathrm{SR}$ de 0,31 , em razão de sua maior sensibilidade ao frio.

Para o aporte de nitrogênio total pelas raízes, a mucuna cinza foi superior ao milheto, sem se diferenciar da $C$. juncea e do feijão-de-porco. Essas diferenças se devem ao teor de nitrogênio encontrado nas raízes dessas plantas (Tabela 1), assim como no caso do carbono das raízes. Estas variações das porcentagens de nitrogênio encontrados no sistema radicular de diferentes espécies correspondem às encontradas por Derpsch,
Sidiras e Heinzmann (1985), que obtiveram entre 2,20\% de nitrogênio para tremoço branco e 1,09\% de nitrogênio para girassol. Para a relação PA/SR do nitrogênio, todas as espécies avaliadas adicionaram mais nitrogênio pelo sistema radicular do que pela parte aérea (Tabela 1).

A distribuição do sistema radicular de todas as plantas de cobertura seguiu o padrão: de um total de 3,56 a 4,21 $\mathrm{Mg} \mathrm{ha}^{-1}$ de massa seca até 1 $\mathrm{m}$ de profundidade, sem diferença entre as espécies (Tabela 1), houve maior concentração de raízes (cerca de 1 a $2 \mathrm{Mg} \mathrm{ha}^{-1}$ ) na camada 0-0,10 m, com percentual de 57,1 a 64,4\%, sem diferenças entre as espécies (Figura 1). A massa seca nas demais profundidades foi de aproximadamente $0,5 \mathrm{Mg}$ $\mathrm{ha}^{-1}$ na camada $0,10-0,20 \mathrm{~m}$ e de aproximadamente $0,2 \mathrm{Mg} \mathrm{ha}^{-1}$ nas camadas seguintes até $1,00 \mathrm{~m}$ de profundidade, também sem diferença entre as espécies. 
Figura 1. Distribuição, por profundidade, do aporte de massa seca das raízes de plantas de cobertura de verão. Santa Maria-RS, 2006.

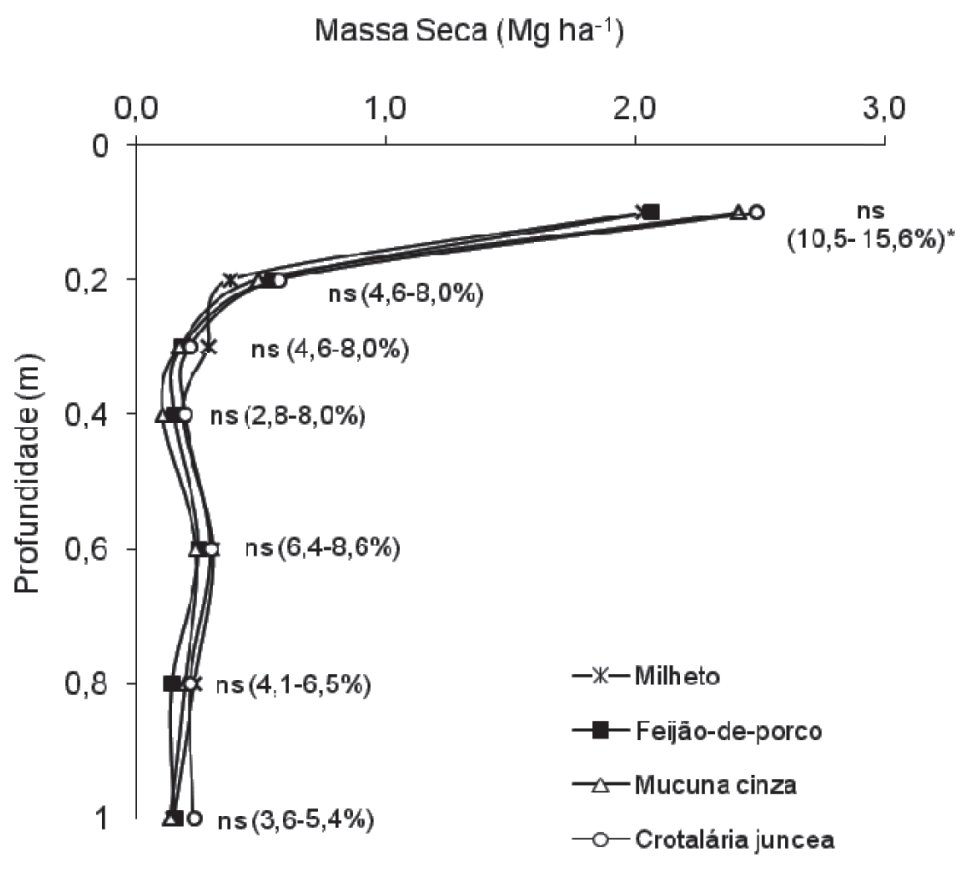

*ns: não significativo pelo teste de Tukey a 5\% de probabilidade de erro. Os números entre parênteses representam a variação da porcentagem de massa seca entre as espécies de plantas de cobertura.

Fonte: Elaboração dos autores.

A densidade de comprimento radicular foi de 3,35 a $3,86 \mathrm{~cm} \mathrm{~cm}^{-3}$ (Tabela 2), sem diferença entre as espécies. Estes valores são menores do que os obtidos para $C$. juncea e maiores do que os obtidos para feijão de porco e para mucuna no trabalho de Alvarenga et al. (1995), nas condições de Viçosa (MG).

A profundidade efetiva (até onde se encontra $80 \%$ do sistema radicular) ficou entre 0,26 para a mucuna cinza, que foi significativamente inferior, e 0,39-0,40 para milheto e C. juncea, sendo a última superior nesse parâmetro (Tabela 2), o que pode proporcionar aumento do teor de matéria orgânica no solo em maiores profundidades, fato que pode estar relacionado aos resultados de Boddey et al. (2010) para as diferenças de acúmulo de $\mathrm{C}$ mais acentuadas a maiores profundidades quando se comparam sistemas de semeadura direta e convencional. Para a profundidade efetiva do aporte de carbono e nitrogênio do sistema radicular, os resultados seguiram o observado para a matéria seca. Estes resultados corroboram com Reinert et al. (2008), que encontraram maior concentração das raízes de mucuna-cinza nas camadas superficiais do solo em relação às raízes de C. juncea. Contudo, Alvarenga et al. (1995), ao caracterizarem as raízes de algumas espécies de plantas de cobertura a campo, observaram distribuição semelhante entre raízes de $C$. juncea e mucuna preta.

Conclui-se que o sistema radicular da $C$. juncea possui a maior profundidade de raízes e, juntamente com o sistema radicular do milheto, aporta a maior quantidade de matéria seca, carbono e nitrogênio em profundidade. 


\section{Referências}

ALBUQUERQUE, J. A.; REINERT, D. J. Densidade radicular do milho considerados os atributos de um solo com horizonte B textural. Revista Brasileira de Ciência do Solo, Viçosa, v. 25, n. 3, p. 539-549, 2001.

ALVARENGA, R. C.; COSTA, L. M.; MOURA FILHO, W.; REGAZI, A. J. Caracteristicas de alguns adubos verdes de interesse para a conservação e recuperação de solos. Pesquisa Agropecuária Brasileira, Brasília, v. 30, n. 2, p. 175-185, 1995.

BALESDENT, J.; BALABANE, M. Major contribution of roots to soil carbon storage inferred from maize cultivated soils. Soil Biology and Biochemistry, Oxford, v. 28, n. 9, p. 1261-1263, 1996.

BAZOT, S.; MIKOLA, J.; NGUYEN, C.; ROBIN, C. Defoliation-induced changes in carbon allocation and root soluble carbon concentration in field-grown Lolium perenne plants: do they affect carbon availability, microbes and animal trophic groups in soil? Functional Ecology, v. 19, n. 5, p. 886-896, 2005.

BODDEY, R. M.; JANTALIA, C. P.; CONCEIÇÃO, P. C.; ZANATTA, J. A.; BAYER, C.; MIELNICZUK, J.; DIECKOW, J.; DOS SANTOS, H. P.; DENARDIN, J. E.; AITA, C.; GIACOMINI, S. J.; ALVES, B. J. R.; URQUIAGA, S. Carbon accumulation at depth in Ferralsols under zero-till subtropical agriculture. Global Change Biology, Urbana, v. 16, n. 2, p. 784-795, 2010.

BÖHM, W. Methods of studying root systems. Berlim: Springer-Verlag, 1979. $188 \mathrm{p}$.

BOLLIGER, A.; MAGID, J.; AMADO, T. J. C.; SKORA NETO, F.; RIBEIRO, M. F. S.; CALEGARI, A.; RALISCH, R.; NEERGAARD, A. Taking stock of the Brazilian "zero-till revolution": a review of landmark research and farmers' practice. Advances in Agronomy, v. 91, p. 47-110, 2006.

DERPSCH, R.; SIDIRAS, N.; HEINZMANN, F. X. Manejo do solo com coberturas verdes de inverno. Pesquisa Agropecuária Brasileira, Brasília, v. 20, n. 7, p. 761-773, 1985.

EMPRESA BRASILEIRA DE PESQUISA AGROPECUÁRIA - EMBRAPA. Sistema brasileiro de classificação de solos. Rio de Janeiro: EMBRAPA Solos, 1999. $412 \mathrm{p}$.

GREGORY, P. J. Roots, rhizosphere and soil: the route to a better understanding of soil science? European Journal of Soil Science, Oxford, v. 57, n. 1, p. 2-12, 2006.
HOKKA, V.; MIKOLA, J.; SETÄLÄ, H. Interactive effects of defoliation and an AM fungus on plants and soil organisms in experimental legume-grass communities. Oikos, Noruega, v. 106, n. 1, p. 73-84, 2004.

HOLANDA, F. S. R.; PEDROTTI, A.; MENGEL, D. B.; CARVALHO, J. G.; SILVA, T. O. da; MELLO JÚNIOR, A. V. Contribution of tillage systems on the organic matter of Gley soil and the productivity of corn and soybean soil and the productivity of corn. Semina: Ciências Agrárias, Londrina, v. 32, n. 3, p. 983-994, 2011.

JORGE, L. A. C.; RALISCH, R.; ABI SAAB, O. J. G.; MEDINA, C. C.; GUIMARÃES, M. F.; NEVES, C. S. V. J.; CRESTANA, S.; CINTRA, F. L. D.; BASSOI, L. H.; FERNANDES, S. B. V. Aquisição de imagens de raízes. In: JORGE, L. A. C. (Ed.). Recomendações práticas para aquisição de imagens digitais analisadas através do SIARCS. São Carlos: EMBRAPA/CNPDIA, 1996. p. 2-28. (Circular técnica, 1).

KLAR, A. E. Irrigação: freqüência e quantidade de aplicação. São Paulo: Nobel, 1991. 156 p.

LOVATO, T.; MIELNICZUK, J.; BAYER, C.; VEZZANI, F. Adição de carbono e nitrogênio e sua relação com os estoques no solo e com o rendimento do milho em sistemas de manejo. Revista Brasileira de Ciência do Solo, Viçosa, v. 28, n. 1, p. 175-187, 2004.

MARQUES, M. G.; AITA, C.; HUBNER, A. P.; GIACOMINI, S. J.; GUIDINI, E.; LUNKES, A.; CADORE, F. Produção de fitomassa e acúmulo de nitrogênio pela seqüência de plantas de cobertura no verão e nabo no outono/inverno e sua influência no milho em sucessão. In: REUNIÃO BRASILEIRA DE FERTILIDADE DO SOLO E NUTRIÇÃO DE PLANTAS, 25., 2002, Rio de Janeiro. Anais... Rio de Janeiro: Sociedade Brasiléia de Ciência do Solo, 2002. CD-ROM.

MONEGAT, C. Plantas de cobertura do solo: características e manejo em pequenas propriedades. Chapecó: Ed. do Autor, 1991. 337 p.

PERIN, A.; SANTOS, R. H. S.; URQUIAGA, S.; GUERRA, J. G. M.; CECON, P. R. Produção de fitomassa, acúmulo de nutrientes e fixação biológica de nitrogênio por adubos verdes em cultivo isolado e consorciado. Pesquisa Agropecuária Brasileira, Brasília, v. 39, n. 1, p. 35-40, 2004.

POST, W. M.; EMANUEL, W. R.; ZINKE, P. J.; STANGENBERGER, A. G. Soil carbon pools and world life zones. Nature, v. 298, p. 156-159, 1982. 
RASSE, D. P.; RUMPEL, C.; DIGNAC, M. F. Is soil carbon mostly root carbon? Mechanisms for a specific stabilization. Plant and Soil, The Hague, v. 269, n. 1-2, p. 341-356, 2005.

REINERT, D. J.; ALBUQUERQUE, J. A.; REICHERT, J. M.; AITA, C.; CUBILLA, M. M. Limites críticos de densidade do solo para o crescimento de raízes de plantas de cobertura em Argissolo Vermelho. Revista Brasileira de Ciência do Solo, Viçosa, v. 32, p. 1805-1816, 2008.

TEDESCO, M. J.; GIANELLO, C.; BISSANI, C. A.; BOHNEN, H.; VOLKWEISS, S. J. Análise de solo, plantas e outros materiais. 2. ed. Porto Alegre: Departamento de Solos da UFRGS, 1995. 174 p. (Boletim técnico de solos, 5).
VENDRUSCOLO, E. R.; AITA, C.; GIACOMINI, S. J.; HUBNER, A. P.; CHIAPINOTTO, I. C.; NICOLOSO, R. S.; ANDRADA, M. C.; FRIES, M. R. Cultivo de plantas de cobertura de verão intercalares ao milho e sua influência sobre a consorciação de aveia preta + ervilhaca. In: REUNIÃO SUL BRASILEIRA DE CIÊNCIA DO SOLO, 3., 2000, Pelotas. Anais... Pelotas: EMBRAPA Clima Temperado e Núcleo Regional Sul da Sociedade Brasileira de Ciência do Solo, 2000. CD-ROM.

ZANATTA, J. A.; BAYER, C.; DIECKOW, J.; VIEIRA, F. C. B.; MIELNICZUK, J. Soil organic carbon accumulation and carbon costs related to tillage, cropping systems and nitrogen fertilization in a subtropical Acrisol. Soil \& Tillage Research, Netherlands, v. 94, n. 2, p. 510519, 2007. 